\title{
Prologue
}

\section{Mustering the marks}

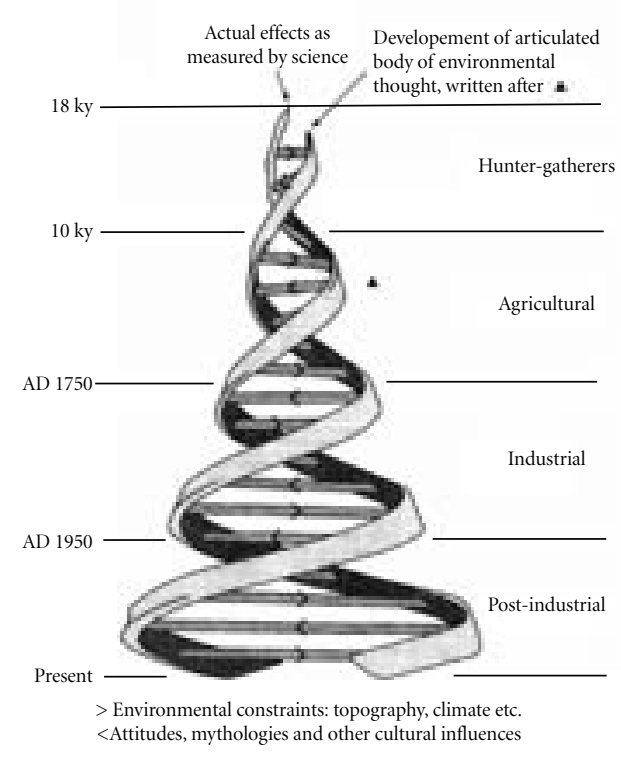

(A)

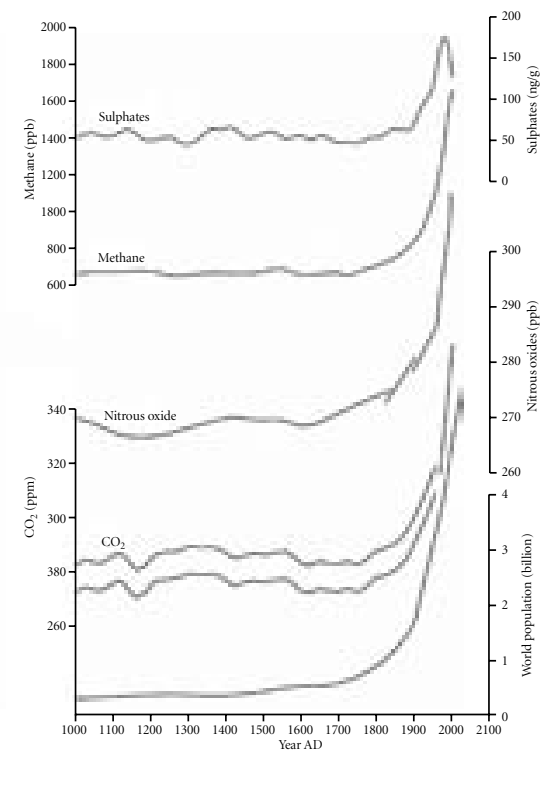

(B)

(A) A simple model of human-non-human interactions on Earth in the last 12,000 years, based on the double helix conception of the DNA molecule. Here, the base pairs represent the influence of the natural on the cultural and vice versa. They should perhaps have different widths according to their strengths at various times, but the size of the diagram does not make that visually effective. In this version, the gyre of the helix is very roughly proportional to the size of the human population, with the downturns pointing out that population growth, while apparently inexorable, can be affected by plagues and pandemics. For greater accuracy, the diagram should be cut off at about the level of the label 'Postindustrial' but that would fail to convey any sense of vulnerability. But this model is mostly a guide to the structure of the material in this book, rather than a direct help to understanding the world.

(B) A set of graphs for the period AD 1000-2000. The lowest curve is a numerical indication of the size of the gyre in $(\mathrm{A})$ and the other 
curves reflect human activities. Carbon dioxide $\left(\mathrm{CO}_{2}\right)$ has a very high profile and represents the take-off of fossil-fuel use in the growth of industrialism, a curve echoed by methane which is a more effective 'greenhouse gas' than $\mathrm{CO}_{2}$ by a factor of twenty-three. It is emitted from human activities that involve anaerobic digestion such as landfills, and the stomachs of cattle. Nitrous oxides, which are emitted by many forms of transport, are also greenhouse gases and fall out from the atmosphere as part of acid precipitation. Like the DNA gyre, these are both cause and effect. The growth in human numbers and the changes in economy increase the quantities of gases emitted to the atmosphere but the curves also symbolise cultural attitudes in which growth in wealth and throughput of resources are regarded as normal and every effort is made to sustain rates of growth rather than level out the curves. One task for environmental history is to chronicle and explain the strength of the interactions between the human and nonhuman worlds in terms of their mutual effects and the creation of hybrid forms.

This initial section of the book is basically an overview of what will be developed later in the text and may therefore allow potential readers to tell if it is the book they are looking for. It contains in brief many of the ideas and themes that are treated at greater length but obviously loses many of the nuances and caveats that pepper the longer chapters. But, in the spirit of the 'executive summary', it contains a compressed version of what follows: it musters together the essence of the printed text ('the marks').

\section{An approach to a complex history}

As a foundation, this narrative emphasises the empirical evidence for change in the last 10-12,000 years. ${ }^{1}$ It is not confined to the material world, however, for it is also concerned with humans' ideas about the planet and their place on it. This inevitably means noticing the debates about the status of knowledge: how do we know what we think we know? This discussion of ideas per se is in Chapter 1, and readers can pass it by if they want the (relatively) simple epoch-by-epoch story. But, even then, there is no escape from discussions of the ideas formulated by various societies together with our recent interpretations of their perceptions and cognitions. There is also an attempt to draw out some abstract themes that carry across the whole timespan of the last 10,000-odd years (with even earlier roots) and which apply to society-nature interactions. These crystallise around notions of fragmentation and individualisation in society on the one hand, and coalescence and uniformity on the other; they are then examined for their impact on the human environment.

There is as well a stance in terms of definitions. A distinction is made between worldwide, in which a material entity is found throughout the world 
but in discrete patches and mostly on the land surfaces (e.g. soil erosion or Sky TV), and global, which is used only when there is the involvement of all the -spheres of the planet, including the upper atmosphere in its capability of diffusing uniformly the gases which it receives more regionally. Global phenomena are thus mostly relatively recent when brought about by humans, though natural climate change (as one example) has always been effective. This brings us up against the modelling of the 'greenhouse effect' and, while this must be included, the book is not about prognostication and is indeed a bit sceptical of the view that environmental history has a great deal to tell us about our future.

\section{States of change}

The world has been in a state of flux since the height of the last glacial maximum of the Pleistocene ( 1.8 million to 11,500 years ago); the postglacial climate is sometimes said to be unusually stable but there have been notable fluctuations: a widespread 'optimum' in the mid-Holocene, sudden descents into cold phases and long periods of intense drought. Recurrent phenomena like the El Niño/La Niña variations in Pacific sea temperatures have experienced measurable fluctuations in frequency and intensity. Yet most of these second-order changes have not been uniform across the planet: there are regional differences in their incidence. There has been a continuous response by living organisms whose populations have grown or fallen and which have changed their distributions. New land surfaces have been colonised, and most human habitats have acquired a characteristic flora and fauna, including micro-organisms. None of the scientific investigations into the last 10,000 years has indicated a stable state of nature.

In addition to these transitions, human societies have changed their ways of life. From a population that was 100 per cent hunter-gatherer (or 'gatherer-hunter' or 'forager' - equivalent terms) and based on food collection from the wild, agriculture became dominant after about 8000 BC, though leaving large marginal areas for the hunters and gatherers. The solarbased agricultural economies persisted until after the mid-eighteenth century when the industrial economies then burgeoning in Europe and North America began to have a strong impact upon them. Although such agriculture has persisted until very recently, it can be argued that a fossil-fuel based industry was the world's major economy until about 1950, when it was intensified to a different level of interaction with the rest of the globe. All these changes (each of which is labelled an era) have been accompanied by a rise in the human population from a few million in 10,000 $\mathrm{BC}$ to just over 6,000 million ( 6 bn) in AD 2000. The main difference between the beginning and the end of this sequence has been a transition from patchy and temporary impacts upon the energy and material flows of the ecosystems inhabited by humans to a partial obliteration of the natural world in a series of very large conurbations together with a considerable degree of alteration of 
the terrain devoted to agriculture, grasslands and forests. Further, the effects wrought by carbon-based industrial activity upon the oceans and atmosphere have made Homo sapiens a species with a truly global reach. ${ }^{2}$

Parallel to this history devoted to alterations in the material world, there are the shifts in ideas about the kind of world we talk about and of the human place in it. There may have been a degree of commonality in most hunter-gatherers' world views as they adapted to circumstances over which they often had only a small degree of control. Agriculture seems to have produced many different interpretations of humans' place and role in the world but industrialisation brought about more uniformity as technologies powered by steam emplaced conquest, colonialisation and the spread of genetically uniform crops. Then, since 1950, there is the phenomenon called 'globalisation' in which instant communication and rapid transport have allowed an intensification and acceleration of most forms of interaction between humans and between humans and the non-human world of the globe: the 'post-industrial' economy. Both the last two eras have spawned countercultures which exist as islands in time as well as space.

Nobody can now imagine that these are stories in isolation from one another. They intertwine and are connected by strands of material flow and of meaning in which separation of either is very difficult. The quantity of food on a plate in the United States, for example, has more to do with the symbolism of plenty and achievement than with what is needed for healthy nutrition. A possible visualisation of these relationships might be the kind of DNA-style double helix, as presented above. Such imagery does not produce explanations and, in this case, it is only an aid to grasping the structure of the thinking behind the book. In fact the approach of this present volume is largely descriptive and even where, at the end, some 'why' questions are approached, it is in the knowledge that there are deeper levels of understanding that need another set of enquiries.

\section{Perspectives}

Even without humanity, the world would have changed and be changing. Humans have, though, produced many alterations which are very different from those of a 'natural' kind. Although the roots were much earlier, the period since 1950 has been the most extensive, the most intensive and the most measured. These features tend to overshadow the fact that each era has had its origins in an earlier phase but, once established, the later epoch dominates the scene. Equally, every subsequent era was not predictable by its predecessors, each of which would have declared itself to be the only way of living. Yet all of them were superseded by changes in the harnessing of energy and the application of that energy through technologies which move within a matrix of social attitudes. Hunter-gatherers, pre-industrial agriculturalists and hydrocarbon-based industry alike would have believed at the time of their zenith that they expected to go on for ever. ${ }^{3}$ 


\section{Notes}

1. There is a number of textbooks which supply long-range and worldwide accounts of the development and activities of human societies. For 'prehistory', see C. Scarre (ed.) The Human Past. World Prehistory and the Development of Human Societies, London: Thames and Hudson, 2005 (784 pages); for later times there is R. Tignor et al., Worlds Together, Worlds Apart. A History of the Modern World from the Mongol Empire to the Present, New York: W. W. Norton, 2002 (462 pages +49 pages of Index); more modestly there is P. Atkins, I. Simmons and B. Roberts, People, Land and Time. An Historical Introduction to the Relations between Landscape, Culture and Environment, London: Arnold, 1998 (a mere 286 pages). There is something of a gap between the chronological coverage of the first two, not filled by any comparable work. For really long-range history (the last 4.5 billion years), see D. Christian, Maps of Time, Berkeley, Los Angeles and London: University of California Press, 2005.

2. Overviews with an environmental emphasis include J. Diamond, Guns, Germs and Steel. A Short History of Everybody for the Last 13,000 Years, London: Chatto and Windus, 1997, Vintage 2005; J. R. McNeill and W. H. McNeill, The Human Web. A Bird's Eye View of World History, New York and London: W. W. Norton, 2003.

3. Doubts about the long-term availability of coal were expressed in the first quarter of the twentieth century, but nobody acted as if they were real. Hence my use of the verb 'believe'. 